Revista Iberoamericana, Vol. LXVIII, Núm. 198, Enero-Marzo 2002, 49-66

\title{
RUBÉN DARÍO Y FRANCISCO GRANDMONTAGNE EN EL BUENOS AIRES DE 1898. LA REDEFINICIÓN DE LOS CONCEPTOS DE HISPANISMO EN AMÉRICA Y DE AMERICANISMO EN ESPAÑA
}

\author{
POR \\ IGNACIO GARCía \\ University of Western Sydney
}

\section{CAMBIO DE ACTITUD}

España y Latinoamérica, que se dieron la espalda durante el siglo XIX, comienzan el xx dialogando. Núcleos hubo en la sociedad americana que fueron siempre hispanófilos en el XIX, en especial sectores vinculados al clericalismo más tradicionalista; y otros en el xx que nunca dejaron de ser hispanófobos. Pero la historiografía del periodo ha detectado claramente cómo la élite cultural -el sector intelectual vinculado al liberalismo conservador en el poder- cambia de actitud al cambio de siglo. Algo análogo sucede en las relaciones que mantiene la intelectualidad española con las excolonias. Pike en su Hispanismo 18981936, por citar quizá el estudio más clásico, sitúa el punto de arranque de esta valoración positiva del hispanismo en América en la publicación en 1900 del Ariel, del uruguayo Juan Enrique Rodó; y el de la decadencia del americanismo retórico en España y su sustitución por un americanismo “de acción” en la visita de Rafael Altamira a América en 1909. En este trabajo se atrasan ligeramente las fechas y se cede el protagonismo al Rubén Darío de 1898, en quien Rodó bebió inspiración para su Ariel, y a Francisco Grandmontagne y su viaje a España de 1903, que ayudará a hacer posible el que en dirección contraria emprenda Altamira. Las actuaciones de Darío y Grandmontagne no se producen independientemente la una de la otra, como para Pike las de Rodó y Altamira, sino que están interrelacionadas; además, apuntamos, sólo se explican en el contexto que crea un protagonista colectivo ignorado hasta ahora: la élite intelectual de la colonia inmigrante española en el Plata.

La hispanofobia de la clase intelectual argentina hunde sus raíces en la Revolución de Mayo de 1810: tras la independencia política había que conquistar la cultural, había que deshispanizar Argentina, porque de España había heredado la excolonia los defectos. El afán deshispanizador llevará, por ejemplo, a evitar la voz "español” para denominar la lengua allí hablada, usando en su lugar la expresión "lengua nacional” porque, como expresa Juan Bautista Alberdi, el gran teórico de la Generación del 37, "[l]a lengua argentina no es la lengua española; es hija de la lengua española como la Nación Argentina es hija de la Nación Española, sin ser por eso la Nación Española”. (Arrieta 77-78)

Para la gran masa, la España es la del himno nacional, que narra cómo los argentinos de 1810 se levantan en armas contra ella "y con brazos robustos desgarran/al ibérico altivo 
león”. La imagen del león humillado, en los versos del himno o en la correspondiente figura alegórica -la mujer vestida de guerrero que representa a Argentina y a sus pies el león, la metrópoli colonial- mortificó a la colonia española en Argentina hasta justamente el año 1900 en que se regula el uso del himno en los actos oficiales de forma que las ofensivas estrofas no se canten. La colonia vivió en su propia carne los efectos de esta imagen negativa de España: de entre todas las poblaciones inmigrantes, excluyendo claro está la negra, la española, la segunda en importancia, fue también la más vilipendiada. (García, "Y a sus plantas” 195)

Si Argentina da la espalda a España, también España da la espalda a América. En la Península, durante todo el xix, las capas cultas tienden a considerar la América hispana como una sociedad racialmente inferior y políticamente sumida en el caos tras haberse sacudido su paternal tutela. El reconocimiento diplomático de los nuevos países fue un proceso lento y torpe, que comienza con el de México en 1837 y no termina hasta 1879 con el de Perú. Los pocos que se interesen por los asuntos de América se agruparán en 1890 en una Unión Iberoamericana, a la que el Gobierno apoyará para contrarrestar el panamericanismo promovido por Washington que pone en entredicho la presencia española en Cuba. Pero es el suyo un americanismo paternalista y retórico, que a los intelectuales americanos les repele. En lugar de fomentar el acercamiento "[l]as fiestas del Centenario colombino han dado el tristísimo fruto de entibiar las relaciones”, escribirá el peruano Ricardo Palma, con Rubén Darío uno de los pocos no diplomáticos que se acercaron a Madrid en 1892 a participar en los congresos que la Unión convocó, pobre remedo del Panamericano de Washington de 1889-90 (Rama 197).

Esta frialdad con la que desde América se responde a los requiebros del americanismo español contrastará veinte años más tarde con el calor con que se reciba en Buenos Aires a la Infanta Isabel, tía de Alfonso xiır a quien representa en las ceremonias del Centenario; o a los intelectuales españoles en sus giras por América, que empiezan siempre en Buenos Aires. No sólo a Altamira: antes, Vicente Blasco Ibáñez y después Adolfo G. Posada y José Ortega y Gasset, fueron objeto de agasajos aún más destacados. Pero para entonces, el lenguaje ha cambiado ya. En los discursos, las repúblicas americanas han dejado de ser las doncellas núbiles necesitadas de la protección paterna para transformarse en hermanas. "Dentro de pocos días, nuestra patria recibirá a sus hijos de América con el efusivo entusiasmo y el calor entrañable de una madre a sus hijos”, se escribe aún en 1900 con ocasión del Congreso Hispanoamericano en Unión Iberoamericana (30 de Octubre). En 1911, Posada (26) utilizará otro lenguaje cuando recomiende a la Junta para Ampliación de Estudios e Investigaciones Científicas perseguir el fomento de las relaciones intelectuales con América evitando paternalismos y reconquistas espirituales: “... no debe tratarse de ninguna empresa de descubrimientos, de penetraciones, sino sencillamente de estudio y de intimidad intelectual con aquellos países”. La España que ignoró el viaje de Domingo F. Sarmiento en los cuarenta recibirá cordialmente a principios de siglo a Darío, a Ricardo Rojas, a José de Ingenieros y a otros. América, que se avergonzaba en el xIx de su herencia española, pasa a manifestarse orgullosa de ella en el xx. Se ve con nuevos ojos a la madre patria. "No es ya la España de nuestros días la misma que desdeñaban nuestros padres por quimérica, por demagógica y por absurda”, escribirá Rojas (27). 
¿Cómo explicar el cambio? Dos son los dos factores que lo provocan: la intervención militar estadounidense en Cuba y la decidida actuación frente a ella de la colonia inmigrante española en el Plata. Pike y la historiografía sobre el tema tiende a tomar en consideración solo el primer factor. No se paran a preguntar por qué sé reaccionó así en 1898 cuando no se había reaccionado de esa manera antes; por qué la anterior política expansionista yanqui en México, por ejemplo, pasó prácticamente desapercibida. Para los intelectuales de la Generación del '37, los Alberdi y Sarmiento ya citados, Estados Unidos es, a pesar de ese expansionismo, el hermano mayor, el modelo a imitar. La intervención militar en Cuba, la primera yanqui fuera de la plataforma continental, hasta ahora considerada como la causa única de este cambio de actitud hacia lo español que experimentó una parte destacada de la intelectualidad latinoamericana, no hubiera tenido las repercusiones que tuvo de no haberse producido en conjunción con el segundo factor que introducimos en este artículo: la decidida actuación de la colonia inmigrante española en el Plata.

Sirva para poner de relieve el peso de esta colonia el que en Argentina vivan hacia 1895 unos 200.000 españoles, cifra que supone el 70 por ciento de todos los inmigrantes españoles en América (excluyendo Cuba y Puerto Rico), la segunda colectividad en número en el país, tras la italiana. En Buenos Aires capital la cifra de residentes españoles se dobla de 40.000 a 80.000 en tan sólo 7 años, y de ellos el 60 por ciento vive en el centro de la ciudad, y ha venido desarrollando una trayectoria asociativa intensa. Buenos Aires, por su parte, es en esos momentos el París Sudamericano, la Cartago del Sur. Quien quiere hacerse valer, Darío, por ejemplo, acaba en Buenos Aires. La moda francesa entra a Sudamérica por su puerto. Las noticias llegan primero a sus grandes rotativas, La Nación y La Prensa, y de ahí se transvasan a todo el subcontinente (Fernández). ${ }^{1}$ Es precisamente en este Buenos Aires y en el seno de esta colonia que las vidas de Darío y Grandmontagne se van a cruzar.

DARÍO, DE LA HISPANOFOBIA AL HISPANISMO

En 1895 comienza la Guerra de Cuba y con ella la xenofobia antiespañola, que se recrudecía en Buenos Aires cada vez que España emprendía alguna de sus aventuras militares en América, alcanza máximas cotas. En las fiestas nacionales se insulta a los españoles en pasquines, en los teatros se obliga a las compañías españolas a cantar el himno, y se les abuchea. Los diarios provinciales cuentan con secciones con títulos como Gallegadas. Se les provoca, en las asociaciones, en los almacenes, con slogans: Mueran los gallegos sarnosos, Abajo los ladrones, y otros que aún duelen más, Muera España, Viva Cuba Libre... Los españoles responden a las agresiones físicas y con cierta frecuencia se producirán peleas, bastonazos, tiros. Pero frente a esta ola de xenofobia la colonia, unida

${ }^{1}$ De lo consciente que se es de esto en el ámbito diplomático da cuenta el despacho de 4 de febrero de 1904 del encargado de negocios al ministro de Estado en el que se habla de "[...] La Prensa, diario que como usted no ignora, es el de más importancia por su gran circulación y más extensamente informado y cuya influencia como órgano del periodismo diario, se extiende con gran profusión a todos los países de América del Sur.” Archivo del Ministerio de Asuntos Exteriores, Madrid, leg. 1354. 
a partir de 1896 en una Asociación Patriótica Española, responderá con una explosión de patriotismo que, en palabras del ministro de España en Buenos Aires rayó en lo inverosímil y causó general estupor. ${ }^{2}$ Se enviaron más de mil seiscientos voluntarios a luchar a las Antillas, quedando en tierra un número superior a los diez mil que no llegó a partir "por indicaciones expresas de la superioridad”; se donó un crucero acorazado de 1.775 toneladas, el Río de la Plata, que se incorporó a la Armada española cuando la guerra ya estaba perdida, y se contribuyó con más de un tercio al total de lo recaudado en la Suscripción Nacional convocada por la Reina Regente para gastos de guerra (García, "Voluntarios” 113-19).

Darío, con la vista puesta en París, había mirado por encima del hombro todo lo que fuera español y no era querido en la colonia. Fernando López Benedito, director de $E l$ Correo Español, el diario de la colectividad, él mismo tenido por poeta y crítico literario de calidad, puede que empañada su visión por prejuicios patrióticos, no valoró su genio poético: “¡Pobre Rubén Darío! Ha perdido el juicio. Véase, véase a qué extremos ha llegado", escribe como comentario al poema "Fresas de invierno" del nicaragüense (El Correo, 24 de junio de 1897). Con el único inmigrante con quien Darío mantuvo contacto fue con el más atípico: Francisco Grandmontagne. Redactor del semanario La Vasconia, Grandmontagne no se dejó contagiar por la fiebre patriótica. Prófugo, pues estaba en edad militar, antepuso su carrera de escritor — publicó Teodoro Foronda en 1896 y La Maldonada en 1898 - al cumplimiento de sus deberes con la patria, que le exigían haberse presentado voluntario. Por ser redactor se sentó en la junta consultiva de la Asociación Patriótica, pero no por eso dejó El Eco de Galicia de zaherirle con cierta frecuencia, llamándole defensor de "incendiarios, asesinos y bandoleros de Cuba” ya en noviembre de 1895; en 1898 cambió su nombre a Luis Jaizquibel en La Vasconia mientras seguía firmando con él en las publicaciones argentinas. ${ }^{3}$ Fue precisamente en los talleres de $L a$ Vasconia que Darío publicó la primera edición de sus Prosas Profanas en 1898. De esta amistad con el poeta se jactará Grandmontagne en sus cartas a Miguel de Unamuno de 1899.

En abril de 1898, cuando la amenaza de la intervención militar yanqui en Cuba se haga inminente, la dirección de la Patriótica dará aliento a aquellos intelectuales argentinos que empiecen a ver que los términos del conflicto no son ya Cuba española frente a Cuba libre, sino Estados Unidos agresor frente a una España arrastrada a la guerra para defender su soberanía, que es lo más sagrado para una nación que se precia. Primero fue Calixto Oyuela - cuyo prestigio como poeta se había fraguado en los Juegos Florales que organizó el Centro Gallego en 1882 y que presidió Rafael F. Calzada, ahora dirigente de la Patriótica - con su “Oda a España” publicada en El Tiempo el 3 de abril. Después, Luis V. Varela, que a petición expresa de Calzada — según el propio Calzada (53) cuentapublicó el 13, también en El Tiempo, el artículo “España y Estados Unidos”, artículo al

${ }^{2}$ Ministro de España a ministro de Estado, 1 de febrero de 1899. Archivo del Ministerio de Asuntos Exteriores, Madrid, leg. 2314.

${ }^{3}$ Firma como Luiz Jaizquibel su artículo "Por el Pilcomayo. Enrique de Ibarreta. Los tobas del Chaco argentino” en La Vasconia, 10 de agosto de 1898; el mismo artículo apareció en La Ilustración Sudamericana 1899: 29, firmado por F. Grandmontagne. A estos incidentes se refiere Grandmontagne en carta a Miguel de Unamuno de noviembre de 1901. Casa Museo Unamuno, Epistolario. 
que contestó en tono también pro-español Julio Herrera y Obes, ex presidente de Uruguay, con su "La cuestión palpitante" el 21. Tras El Tiempo, otros periódicos, Tribuna, El Diario, antes calificados de laborantes, pasan a apoyar las posiciones de la colonia.

La Patriótica utiliza la fiesta nacional del Dos de Mayo para convocar un mítin en el Teatro Victoria de Buenos Aires que resalte esta nueva tendencia y sirva para recaudar fondos para la mencionada Suscripción Nacional. En él pronuncian discursos, en representación de Italia, Francia y Argentina - “madre”, "hermana” e "hija” de España en el referente simbólico de la época - el italoargentino José Tarnassi, el francoargentino Paul Groussac y el que será futuro presidente Roque Sáenz Peña, vinculado éste entonces precisamente al periódico El Tiempo, y que ya en el primer Congreso Panamericano de Washington en 1890 había dado la nota discordante pronunciando frente a la máxima Monroe su "Sea América para la humanidad”. En el mítin del Victoria, Sáenz Peña condenó la intervención americana: la doctrina Monroe, “América para los americanos” se opuso siempre a la intervencion europea en América, pero no a la estadounidense. La doctrina McKinley, por el nombre del presidente entonces en Washington, no es una ruptura con la doctrina Monroe como había supuesto Varela — esta antiintervencionista, aquella intervencionista - sino su corolario: “Condenar las intervenciones europeas en el mismo documento en que se reservan las americanas y en que ellas se ejercitan por acto propio e inconsulto, no es, en efecto, reprobar la intervención, sino gestionar su monopolio". ${ }^{4}$

Con la atención centrada en el tema de Cuba, el eco de la velada del Victoria se transmitió a todo el subcontinente. Pero nos interesa más resaltar ahora el impacto que causó dentro del mismo Buenos Aires en uno de los asistentes al mítin: Rubén Darío. Bajo la directa influencia del Victoria, nos dice, publicó el 20 de mayo en El Tiempo su "El triunfo de Calibán”. En este histórico artículo que Jaúregui (441-47) rescató poco ha del olvido, Darío señaló cómo la intervención militar de Estados Unidos en Cuba fue, también para él, el hecho que determinó su cambio de postura:

Y yo, que he sido partidario de Cuba libre, siquier fuese por acompañar en su sueño a tanto soñador y en su heroísmo a tanto mártir, soy amigo de España en el instante en que la miro agredida por un enemigo brutal, que lleva como enseña la violencia, la fuerza y la injusticia.

Añadía no estar de parte “de esos búfalos de dientes de plata”, aborrecedores de la sangre latina, cuyos ideales quedaban circunscritos a la bolsa y a la fábrica, y proponía, en el espíritu de los oradores del Victoria, crear frente a la unión anglosajona, a la tácita alianza entre Inglaterra y Estados Unidos, una Unión Latina, como instrumento de defensa frente al materialismo anglosajón. Negaba, por otro lado, que su nueva postura reflejase falta de coherencia con planteamientos que hubiera defendido antes:

“Y usted, ¿no ha atacado siempre a España?” Jamás. España no es el fanático curial, ni

\footnotetext{
${ }^{4}$ Los tres discursos aparecen publicados en los principales periódicos de Buenos Aires el 3 de mayo.
} La cita está tomada de la versión que ofrece El Correo Español. 
el pedantón, ni el dómine infeliz, desdeñoso de la América que no conoce; la España que yo defiendo se llama Hidalguía, Ideal, Nobleza; ... se llama la Hija de Roma, la Hermana de Francia, la Madre de América.

¡Miranda preferirá siempre a Ariel; Miranda es la gracia del espíritu; y todas las montañas de piedras, de hierros, de oros, de tocinos, no bastarán para que mi alma latina se prostituya a Calibán! $!^{5}$

Como se ha mencionado, es frecuente señalar al Ariel de Rodó como el texto que marcó el punto de arranque de un hispanismo de nuevo tipo en América, ajeno al defendido desde siempre por los sectores católicos más tradicionalistas. No es raro encontrar autores como Balbuena Briones que sostienen que la actitud hispanófila de Darío en Cantos de Vida y Esperanza tiene su origen en este Ariel (Balbuena Briones 205). Nada más lejos de la verdad. Rodó, lo que hace en Ariel es continuar el tema iniciado por Darío en "El triunfo de Calibán”, que Rodó conocía muy bien como se puede apreciar leyendo su artículo “Rubén Darío. Su personalidad literaria”, que apareció publicado en La Ilustración Sudamericana en ese mismo año de 1898 (164-65). ${ }^{6}$

No tuvo tiempo Darío de forjar lazos personales con la comunidad española cuando ya estaba navegando rumbo a la Península como corresponsal de La Nación para tomar el pulso a España, reciente aún la derrota. En abril de 1900, en medio de la ola de entusiasmo confraternizador hispano-argentino que se inicia con la visita del buque escuela Sarmiento a Barcelona - y que servirá de pretexto al presidente Julio A. Roca para regular el uso del himno evitando que se cantaran en actos públicos las estrofas ofensivas a los españolesDarío continuará proponiendo en La Nación que "quizá no sería mala la idea de un panhispanismo americano por emergencias más que probables en el futuro". En la redacción de El Correo, López Benedito todavía no se lo puede creer: "Vaya, que le dure a Rubén Darío la intención por muchos años, o siquiera por muchos meses” (25 de abril de 1900).

Al contrario que en el 1892, en esta su segunda visita, España a Darío le encanta. A través de contactos que Grandmontagne le ha facilitado, se entrevista con Unamuno y con Ramiro de Maeztu, dos autores con los que el vasco mantiene regular correspondencia desde Buenos Aires, y a través de ellos, con los demás hombres del '98. Su relación con estos escritores llegará a ser tan íntima que llevará a José Martínez Ruiz, Azorín, el inventor del término, a declarar: "Hombres de la generación del 98 son Valle-Inclán, Unamuno, Benavente, Baroja, Bueno, Maeztu, Rubén Darío” (910).

En Madrid, en 1905, la Unión Iberoamericana, de la que El Correo era entonces órgano oficial en América, recibe en Madrid como a uno de sus "más inteligentes y activos propagandistas” a López Benedito en su primera visita a España tras más de 30 años de ausencia. En el curso de la velada que se celebró en su honor, Darío recitó un soneto, poco citado ahora pero que, oportunamente malinterpretado, fue muy popular durante la primera etapa del franquismo:

\footnotetext{
${ }^{5}$ Citado de El Tiempo, 20 de mayo de 1898; Jaúregui (451-55) ofrece versión editada y comentada. ${ }^{6}$ Este artículo confirma, pues, la acertada intuición de Jáuregui (444) de que Rodó conocía "El triunfo de Calibán”.
} 


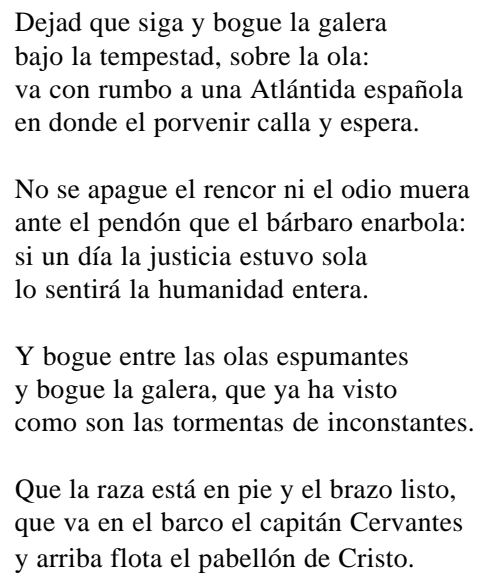

Este soneto, publicado en la primera página del siguiente número de Unión Iberoamericana (16 de junio de 1905) no es tanto un homenaje personal a Benedito, con quien - ya se ha visto - las relaciones no fueron cordiales en el pasado, como a toda la colonia española del Plata en reconocimiento a su papel de partera de esta que fue su nueva religión: el hispanismo. Su hispanofilia sigue a caballo de su carrera literaria, manifiesta en dos de los más famosos poemas que aparecen en su obra cumbre, Cantos de vida y esperanza: "Salutación del optimista” y “A Roosevelt”.

América, que consideraba a España como la cuna de los males de la raza, pasa a considerarla como la cuna de sus virtudes. Gracias a los españoles del Plata, la conmoción que la guerra hispano-norteamericana causó, afectó no sólo a las fronteras geográficas del imperio español, sino a las ideológicas de toda América. No hay intelectual de nota que repita ya en el xx los discursos antiespañoles del xix. Darío no es el único responsable de este cambio, pero es de los primeros y el más influyente de los que se apuntan a él.

INSTITUCIONISTAS Y MODERNISTAS

Darío llegó a España en un momento en que la situación de derrota y de frustración en la Península contrastaba con el extraordinario optimismo que, dejada atrás la crisis de 1890, se respiraba en Argentina. Llegó a anunciar la buena nueva: América rogaba a la madre patria se levantase de su postración, se colocase a la vanguardia de la lucha de la raza. Lo que no dejaba de ser una metáfora, los oídos atentos de la Unión Iberoamericana lo interpretaron al pie de la letra.

De cuál era el tenor de las intervenciones de los prohombres de la Unión da cuenta esta cita con la que se da a los americanos la bienvenida al Congreso Social y Económico Hispano Americano que convocó en 1900: “Acerquémosnos a nuestros hijos para besarles en la serena frente, y sea la vieja y vencida España, la nación cuyo espíritu se imponga en este futuro siglo en el que deberán decidirse los destinos de la raza”. (Unión Iberoamericana, 
15 de mayo de 1900). El objetivo que estos prohombres perseguían: “el que nuestra Patria sea el núcleo, el lazo de unión intelectual, moral, económica y a ser posible política de las repúblicas hispanoamericanas”. (30 de mayo de 1900). Con harto sentido común, Vicente G. Quesada, ministro argentino en Madrid, escribiría a Buenos Aires: “... los españoles [suponen] que a ellos se reserva la dirección de nuestra vida internacional, cuando ni los propios problemas de la Península pueden resolver con acierto y equidad”. ${ }^{7}$ ¡Vivían de espaldas a América!

En el congreso de 1900, empujada por la Unión, España se arrogó el título de Directora de Hispanoamérica, pero las jóvenes repúblicas no corrieron a cobijarse bajo su tutela. No era suficiente anunciar la buena nueva, había que darla a luz, y para ello se requería algo más que discursos y poemas: se requería fomentar las relaciones intelectuales, políticas y comerciales. El mismo Darío, más consciente de ello que muchos personajes de la Unión, había escrito con referencia a estas últimas:

Tales formas de relación entre España y América serán seguramente más provechosas, duraderas y fundamentales que las mutuas zalemas pasadas de un iberoamericanismo de miembros correspondientes de la Academia, de ministros que taquinan la musa, de poetas que "piden” la lira. (Abellán 52)

Frente a la tendencia a interpretar metáforas al pie de la letra, tanto en España como en la colonia española en el Plata, modernistas e institucionistas van a unir fuerzas, a menudo practicando el entrismo en la misma Unión Iberoamericana, para formular un nuevo tipo de americanismo, la cara española de la moneda del hispanismo. A través de Rafael María de Labra, y de Altamira y sus colegas de núcleo neokrausista de Oviedo, el institucionismo — que va a englobar a lo más selecto del reformismo liberal en España, en la política y en la enseñanza, en la filosofía y en la ciencia, hasta bien entrado el siglo xxva a ser una de las fuerzas que den forma y contenido a ese americanismo que romperá con el retórico y tutelar dominante. La otra lo será el modernismo, con su énfasis por adaptar las corrientes europeas a la idiosincrasia hispana, por descubrir, tras haber roto con una tradición presumida ineficaz, su propia originalidad en lo hispano. Con Darío, el modernismo en América da tono a este hispanismo nuevo, que no es ya la prolongación del tradicionalista y clerical que había pervivido en los márgenes de la conciencia continental desde la independencia. Con Unamuno y Maeztu, el modernismo español, o la Generación del ’98 si se prefiere que, como señala José Luis Abellán, no pasa de ser sino una de las versiones peninsulares del modernismo finisecular, da por su parte tono a este nuevo americanismo que los institucionistas buscaban levantar. El modernismo proporcionó el vocabulario, creó el rito, popularizó el concepto. Pero para que el concepto germinase se necesitaba el empeño de ponerlo en práctica. El institucionismo, más concernido por la sustancia que por la imagen, con su énfasis en la educación y en la ciencia, más compromiso que moda, será el precipitante que haga realidad el nuevo americanismo.

Nótese que el modernismo español (a quien Unamuno bien puede representar) establece contacto personal con el americano (que tiene a Darío como líder indisputado)

${ }^{7}$ Despacho fechado el 9 de diciembre de 1900. Archivo de la Cancillería de la República Argentina, Buenos Aires, caja 719, exp. 93. 
a través del único modernista de que la colonia española en Buenos Aires podía presumir, Francisco Grandmontagne, y discutiendo sobre una obra suya: La Maldonada. Unamuno publicó “La Maldonada, costumbres criollas, por F. Grandmontagne” en La Época, el 10 de abril de 1899. Darío le respondió con otro artículo elogiando la obra de Grandmontagne en La Nación de Buenos Aires, al que contestó también en La Nación Unamuno con su “Sobre la literatura hispanoamericana. A Rubén Darío”, publicado el 19 de mayo de 1899.

La colonia española en Buenos Aires, que ayudó a alumbrar este hispanismo, jugó asimismo un importante rol en establecer una corriente americanista en la Península con la que fuese compatible. Esta ayuda la prestó la colonia también en claves modernista Grandmontagne- e institucionista - Antonio Atienza y Medrano. Atienza, uno de los fundadores de la Institución Libre de Enseñanza en 1876, fundador y director en 1888 del periódico La Justicia, órgano del Partido Centralista Republicano de Nicolás Salmerón, emigra en 1889 a Buenos Aires donde alcanzará prestigio como educador y como redactor de La Prensa. A partir de 1903 presidirá la Patriótica que, tras sobrevivir la derrota, conocerá una nueva época de relativo esplendor, ahora no ya con el objetivo de los años heroicos de 1896-97 de "[s]alir en defensa del buen nombre y del honor de España cuando fuere necesario" — no era tan necesario— sino con el más regeneracionista de "[f]omentar el espíritu de confraternidad entre españoles y americanos”. ${ }^{8}$ Grandmontagne, el patriota tibio durante la guerra, fue precisamente su mano derecha en el comienzo de su presidencia de la Patriótica.

Había emigrado a Argentina en su primera juventud, a finales de los ochenta. ${ }^{9}$ En carta a Unamuno se desahogaría más adelante contándole su vida:

No estoy descontento de mí mismo: criado de napolitanos, pobres agricultores; pastor luego; segador de alfalfa, gaucho, peón de estación, albañil, fundidor, despachante de aduana, escritor ... creo que, evidentemente he ido ascendiendo. . . Vine en calidad de carne de inmigración, tirado con 2.000 más sobre la cubierta del Equateur, con pasaje subsidiario. .. Si Ud. supiera cómo he estudiado lo poco que sé: bajo los carros, al pie del caballo, en los ranchos, entre los alfalfares. ${ }^{10}$

Se inició como escritor en La Vasconia, revista que su amigo, el tipógrafo José R. de Uriarte fundó y componía, y Grandmontagne escribía tras acabar su trabajo de despachante de aduanas en la firma Fayant-Causeau. La Ilustración Sudamericana, que Atienza fundó a principios de los noventa y dirigió durante unos años, le publicó también colaboraciones. Para 1903 era ya un periodista notable, quizás más interesado ahora en los problemas de la patria de lo que lo estuvo durante la segunda mitad de los noventa.

En 1903, Atienza funda como órgano de la Patriótica la revista España, que dirigirá hasta su temprana muerte en 1906. En ella tendrán cabida artículos de sus contactos en España, los institucionistas Francisco Giner de los Ríos, Nicolás Salmerón, Altamira y

${ }^{8}$ Fines 2 y 4, Artículo 2 de los Estatutos de la asociación, citados de El Correo Español, 22 de marzo de 1896.

${ }^{9}$ En Grandmontagne (Una gran potencia 16 y 267) dice haber llegado en 1887, y a los 17 años, que sería en 1886 si utilizamos la partida de 30 de septiembre de 1869 citada en Tellechea Idígoras (17). ${ }^{10}$ De Grandmontagne a Unamuno, noviembre de 1901. Casa Museo Unamuno. Epistolario. 
Posada entre otros; y de sus contactos argentinos, el más destacado de ellos Joaquín V. González, la figura clave del segundo roquismo. A esta prestigiosa nómina de colaboradores se ha de sumar los nombres que acerca Grandmontagne, los de Unamuno y Maeztu de la Península, con quienes se carteaba desde mediados de los noventa, y el del argentino Miguel Cané, que con su prestigio había abierto al vasco las puertas en los principales periódicos de Buenos Aires.

España se lanza no sólo con el objetivo de establecer relaciones intelectuales, superando el discurso estéril que domina en la Unión Iberoamericana, sino para promover también las comerciales. La élite de la colonia española que se ve reflejada en la revista, de orientación mayoritariamente republicana, está empeñada en ayudar a España a transformarse en un país moderno como lo es Argentina; partidaria firme del regeneracionismo, no quiere tanto que Argentina imite a España como que España imite a Argentina. Tiene incluso un interés material en promover el contacto económico: las grandes fortunas españolas en el Río de la Plata se hacen en el comercio. Pero no es mucho lo que desde las páginas de una revista se puede conseguir. Es ese el momento en que Atienza, que estaba muy bien considerado en La Prensa, consigue para Grandmontagne el trabajo de corresponsal de este periódico en España al morirse el que lo era, Núñez de Arce. Con el viaje, Grandmontagne va a transformarse en el vehículo de la élite progresista de la inmigración española en el Plata para romper el control que la capa dirigente de la Unión Iberoamericana había impuesto a las relaciones intelectuales y comerciales con América. En la Península, arremeterá contra este americanismo retórico primero a través de lo que se conoció como “misión Grandmontagne” en 1903-04, y después a través de la posición que mantuvo en el asunto de la Universidad Hispanoamericana en 1904-05. Su intervención contribuirá a situar al americanismo de acción en mucha mejor posición que la que tenía al comenzar la década.

GRANDMONTAGNE Y EL OCASO DEL AMERICANISMO RETÓRICO Y PATERNALISTA

La Patriótica decidió que lo más apropiado al objeto de informar sobre "los obstáculos que ofrece el desarrollo de las relaciones comerciales entre España y la República Argentina, y sobre la manera más eficaz de orillarlos o vencerlos” era la de enviar en misión comercial a Grandmontagne, que viajaba ya a ocupar su puesto de corresponsal de La Prensa, y a ese efecto le pagó generosamente las cinco conferencias que le comisionó. ${ }^{11} \mathrm{El}$ sector tradicionalista, minoritario pero ruidoso, criticó mucho esta decisión. Claro que la enemistad de Grandmontagne con el músico Félix Ortiz y San Pelayo, líder de ese sector, venía ya de antes: "Se hace más por la patria vendiendo aceitunas españolas que ensayando un himno de confraternidad hispanoamericana, del cual nos reímos todos hispanoamericanamente”, escribiría con sorna en mayo de 1900, menospreciando los esfuerzos de éste por convocar a toda la colonia a cantar un tema que había compuesto en agradecimiento a la República Argentina por la decisión tomada por el presidente Roca de regular el uso del himno de forma que no se cantasen las estrofas ofensivas. $^{12}$

\footnotetext{
${ }^{11}$ Citado de España 12 (1903): 9.

${ }^{12}$ Se reproduce la cita en España, 12 (1903): 17.
} 
Méritos no faltaron a Grandmontagne para encabezar esta misión: había trabajado mucho tiempo de despachante de aduana y estaba familiarizado con el régimen arancelario. De que se tomó la misión con interés da cuenta su correspondencia con Maeztu: "Voy a poner el resto de mi vida y toda mi alma al servicio de popularizar en España las cosas de América, sus hombres, sus costumbres, y a señalar el camino que allí se abre a la energía española". ${ }^{13}$

Maeztu, a través de la páginas del Diario Universal de Madrid, preparó su llegada a la Península, citando fragmentos de la carta mencionada. Mariano de Cavia, en El Imparcial le llamó “embajador a la moderna”. Con estas conferencias, que se comenzaron a leer a finales de 1903, se intentó apoyar el esfuerzo exportador de España indicando qué mecanismos podrían fomentarlo y cuáles lo obstaculizaban. Las dos de Bilbao se centraron en la industria del hierro, las de Barcelona en la textil y la de Zaragoza en la vinícola. Salpicadas de escándalo por su estilo fieramente laico y liberal, sirvieron para que la voz del sector más representativo de la colonia se oyera alta en la Península. La comunidad de lengua no es vínculo suficiente para el intercambio de relaciones útiles, fue una de sus advertencias. "Será la lengua, como vulgarmente se dice, el vehículo del espíritu, pero ¿qué vale el vehículo si va vacío?"14

Nos referiremos tan solo aquí a la primera de Bilbao. Con recibos que trajo de Buenos Aires, el portavoz de la Patriótica demostró que la Compañía Trasatlántica, que recibía una subvención del Gobierno español de ocho millones de pesetas anuales, cobraba menos de la mitad a los productos fletados en Génova que a los que transportaba desde Cádiz. Este tipo de proteccionismo, señaló, situaba a la industria española en inferioridad de condiciones para exportar.

¿Hay un Gobierno en mi patria que subvenciona a una compañía de navegación que me cobra doble flete que a mi colega italiano de enfrente? ¿Hay un Congreso, un cuerpo legislador, representante de los intereses de mi país, que ignora los efectos de tal prima acordada por su voto? ¿Hay en España una prensa que permanezca muda ante este asesinato de la exportación española? ¿Hay, por fin, un pueblo que pague una subvención para que lo arruinen?

El permitir que la situación continuara, añadía, no entraba ya en el campo de la teoría económica sino en el de la corrupción política.

La conferencia se tomó, un tanto exageradamente, como una arenga revolucionaria contra la Monarquía. El Imparcial comentó: "El conferenciante, en vez de explanar su anunciado tema sobre las relaciones comerciales entre España y América, se ha dedicado a atacar los defectos del carácter español, calificando a los españoles con injustos epítetos” (19 de noviembre de 1903). En el mismo El Imparcial recibió sin embargo el apoyo decidido de Miguel de Unamuno que, lejos de escandalizarse porque en una conferencia comercial se hablara de la intolerancia religiosa, argumentó la estrecha relación existente entre el aumento del intercambio comercial y el libre intercambio de ideas (28 de noviembre).

\footnotetext{
${ }^{13}$ Se reproduce la carta en España, 13 (1903): 4.

${ }^{14}$ España 21 (1903): 5 y ss., donde se reproduce la primera conferencia de Bilbao.
} 
A causa de esta conferencia se dirigieron al Gobierno enérgicas interpelaciones en el Congreso y en el Senado para que se le expulsara de la Península. Ecos del escándalo llegaron a Buenos Aires llevando a la junta ejecutiva de la Patriótica a tomar la decisión de dirigirse telegráficamente a la prensa de Madrid desligándose de cuantas declaraciones hubiera hecho su representante extrañas a la misión comercial que se le había confiado. Conocido el texto de la conferencia, sin embargo, se volvió a enviar otro de felicitación, rogándole prosiguiera su patriótica misión. ${ }^{15}$ Al parecer, gran parte de este revuelo fue debido a que el marqués de Comillas, hombre con influencias en muchos periódicos y en muchos despachos, no encajó bien la acusación que Grandmontagne hizo a la Trasatlántica, de la cual era presidente. Con todas sus influencias, el marqués de Comillas - también importante patrocinador de las actividades de la Unión Iberoamericana - no pudo impedir, sin embargo, que la campaña continuara. El sector institucionista vinculado a la Unión (Altamira en primer lugar) supo sacar partido de este escándalo y de la correspondiente crisis que causó para reforzar sus posiciones dentro de ella.

Un año después se librará otra batalla que resquebrajará aún más la autoridad del grupo dominante en la Unión. La gran aspiración de esta entidad, sacando de quicio una sugerencia que habían hecho los propios institucionistas en 1900, era la de establecer en Salamanca una Universidad Hispanoamericana, para lo que pedía al Gobierno de Madrid que gestionara ante los Gobiernos hispanoamericanos la aprobación de su plan de estudios y el que estos Gobiernos pensionaran a los estudiantes de sus países a acudir a ella, en vez de a otras universidades europeas como solían. A mediados de 1904 y con el semivitalicio presidente de la Unión Faustino Rodríguez de San Pedro entonces ministro de Estado, la iniciativa cobró vuelos apoyada por el Claustro de la Universidad de Salamanca, el rector de la de Madrid, el Conde de Romanones y, al parecer, Antonio Maura y el propio Rey. Su más firme promotor resultó el médico Francisco Cobos, recién llegado de Buenos Aires donde había presidido la Patriótica en 1900 y a quien el sector, si minoritario, de la colonia en el que le paternalismo retórico de la Unión encontraba eco había encomendado el proyecto.

Cobos, que cruzando el Atlántico se transformó en Francisco de los Cobos, cumplió su misión “con tesón, entusiasmo, energía y perseverancia” (Atienza 3). Visitó al presidente del Consejo de Ministros, general Azcárraga, y al Rey, y dio conferencias en el Ateneo de Madrid y en el Paraninfo de la Universidad de Salamanca. Las peripecias de su campaña monopolizaron por semanas las columnas de la prensa española. Implícito en el mensaje que difundía Cobos parecía hallarse el interés de importantes personalidades argentinas en el proyecto: borrada ya la leyenda negra de la dominación española, darían todo género de facilidades. Escribía El Imparcial:

El propósito corresponde a los altos y nobles anhelos de nuestros hermanos del Plata, al deseo de muchas autorizadísimas personas argentinas y al de no pocos españoles que aquí aspiran a unir, con vínculos eternos, los de la ciencia, a pueblos que hablan el mismo idioma y viven en el mismo ambiente de historia y de aspiraciones. (Hernández Díaz 402)

\footnotetext{
15 “Las conferencias de Grandmontagne en España. Falsas alarmas. Restablecimiento de la verdad”, España, 21 (1903): 1.
} 
Sorprendentemente, las únicas reticencias al proyecto serán las de Altamira, catedrático de la americanista Universidad de Oviedo, y las de Unamuno, rector de la Universidad de Salamanca, que iba a ser la beneficiada. Veamos las razones.

Unamuno mostró su falta de entusiasmo en el artículo que publicó precisamente Unión Iberoamericana:

Algunas veces se habla de atraer a España a alguna parte de la juventud americana a la Universidad Internacional y otras empresas, de atraerla para enseñarla; y yo me digo: “Enseñarla, ¿qué?” Es mucho lo que tenemos que aprender antes de enseñar a nadie ... Aún pretendemos ser metrópoli y queremos mantener como colonias espirituales nuestras a las que lo fueron en el orden económico y político. Y pudiera ser muy bien que, en vez de que tengan que venir acá ellos a imbuirse de moderna cultura europea, seamos nosotros los que tengamos que ir allá a ello (1 de marzo de 1904).

Cuanto más estudia el asunto, más irreal le parece. Tras escuchar el discurso de Cobos en el Paraninfo, rememora en El Heraldo de Madrid:

Dije bien claro y ahora lo repito, que semejante proyecto me parece, hoy por hoy, fantástico y absurdo. Reconozco las buenas intenciones y los laudables propósitos de los que patrocinan la idea, pero creo firmemente que pierden el tiempo. La verdad es que ni aquí nos interesamos gran cosa de lo que a América respecta ... ni los americanos sienten ganas de venir acá. Piensan que no hay cosa alguna que puedan aprender en España mejor que en Francia, Alemania, Italia o Inglaterra, ya que en cuanto al castellano saben el suficiente para entenderse y muchos de ellos repugnan, y con razón, nuestras pretensiones al monopolio de su pureza y casticismo. Lo que dije en el banquete al Dr. Cobos y ahora repito, es que movimientos como el que este entusiasta y benemérito español provoca nos deben servir para fijarnos en aquellas naciones de lengua española y estudiar las causas de su desvío, que no son otras que el espíritu de intolerancia y exclusivismo que nos domina. ${ }^{16}$

¿Por qué califica el proyecto de “fantástico y absurdo” con tal seguridad? La correspondencia que mantiene con Francisco Grandmontagne nos lo explica. Él es quien, confidencialmente, le informa "sobre el Sr. de los Cobos (en Buenos Aires siempre le hemos conocido bajo el sencillo nombre de Francisco Cobos)" cuando toda la prensa española habla de él. Como médico, escribe, "Cobos, ni pincha ni corta” en Argentina. Sobre su misión, la califica con los mismos adjetivos de "absurda” y “fantástica”. Para que se realice, le dice, se necesita que los americanos acudan:

Es inútil soñar con que vengan aquí jóvenes americanos, mientras España no tenga en el mundo cartel de cultura. Y aún así, sería difícil, porque los americanos, a la vez que perfeccionan sus estudios, quieren aprender otro idioma ... ¿ Y qué necesidad hay de una Universidad especial? Con poner el nombre de "Universidad Hispano-Americana" a cualquiera de las existentes, ya está todo arreglado. No hay más que esperar a los discípulos.

\footnotetext{
${ }^{16}$ Se adjunta, s. f., en nota confidencial del ministro argentino en Madrid de 5 de enero de 1905.
} Archivo de la Cancillería. Legaciones y consulados extranjeros. España, caja 893, exp. 1. 
Grandmontagne le ponía el ejemplo del duque de Tamames, diputado por Salamanca cuyos hijos se habían educado en Londres y en París. "En cuanto a los hijos de políticos españoles, todos están en Alemania, Inglaterra y Francia. ¿Cómo se ha de pretender que vengan a España los americanos?” Conocedor de la situación en Buenos Aires, concluye:

Cobos no trae la representación de la Asociación Patriótica, que es la institución que allá toma las iniciativas de cierta magnitud. Creo que habla en nombre de asociaciones de carácter recreativo. El proyecto no puede tomarse en serio por su imposibilidad presente, y ese pueblo debe salir del error de esa ilusión. Y si no sale, el tiempo le sacará. ${ }^{17}$

También para entender la posición de Altamira hay que mirar a Argentina. En las páginas de España $(75,1905: 1)$ escribió Altamira un artículo sobre el tema. Señalaba en él cómo "de lo que se trata no es de fundar un establecimiento docente, mejor o peor, sino de atraer a la juventud americana que viene a Europa a completar sus estudios” y que prefiere hasta ahora las universidades francesas y alemanas. Añadía que, aparte de excepciones como las de Cajal para la Histología, Giner para el Derecho e Hinojosa para la Historia, "no podemos presentar un profesorado capaz de hacer la competencia a cualquiera otro extranjero” de los que atraen a los estudiantes sudamericanos y, quizá, más valiera "no acometer la empresa, aunque es muy halagadora, que exponerse a un fracaso". Hacía también la pregunta clave: ¿qué piensan los americanos, puesto que es un proyecto se dice concebido en obsequio a ellos? ${ }^{18}$

Antonio Atienza, que había sido director de La Justicia cuando Altamira trabajaba allí de periodista, le respondió en la misma España desde el otro lado del Atlántico. "No piensan nada: ... pruébalo hasta la evidencia el hecho de que no han comentado en ninguna forma, ni han despegado los labios. Han leído los telegramas de España, en que se relataba la brillante jira del doctor Cobos, se han encogido de hombros y han seguido adelante”. Si se crea, continúa, los americanos "no acudirían a ella a hacer sus estudios, ni a perfeccionarlos, sino seguirían concurriendo a los institutos científicos de Francia, Inglaterra y Alemania”. La manera de atraer a los estudiantes americanos a la Península, añadía, no pasaba ahora por fundar centros universitarios:

Lo que debemos hacer es redoblar el esfuerzo, para que llegue el día en que sea posible lo que hoy es absolutamente quimérico, y apelar entre tanto a recursos más fáciles, para establecer relaciones científicas entre América y España, poniendo en práctica, entre otros, el medio propuesto por Rafael Altamira de enviar temporalmente profesores americanos a dar enseñanza en las universidades españolas, y de que vengan profesores de la península a explicar en las universidades americanas (4). ${ }^{19}$

\footnotetext{
${ }^{17}$ Carta fechada 19 de diciembre de 1904. Casa Museo Unamuno. Epistolario. Envió artículo a La Prensa de Buenos Aires en términos similares, de donde lo citará R. Altamira (180).

${ }^{18}$ Se muestra claramente en este artículo que Altamira no está a favor del proyecto, en contra de lo que Hernández Díaz (402) sugiere.

${ }^{19}$ Altamira (1908: 371 y ss.) reproducirá este artículo.
} 
Cuán acertadas eran las opiniones que los Grandmontagne y Atienza de Buenos Aires comparten con los Unamuno y Altamira de España lo corrobora la correspondencia entre el representante de la diplomacia argentina en Madrid, Vicente G. Quesada, y sus superiores en Buenos Aires. En nota confidencial del Ministro argentino fechada el 5 de enero de 1905 y en relación con una entrevista que mantuvo con una delegación de la Unión Iberoamericana se lee:

El solo proyecto de que mostrábanse mis distinguidos visitantes tan ufanos revelaba en ellos la convicción de que España, divorciada de su siglo, cuyos códigos aún consagran todas las "censuras" que hacen de la libertad un mito, retrógrada y monárquica, puede ser el centro de atracción intelectual para la progresiva América, republicana y demócrata [...] Por fortuna, el señor Unamuno, rector de la otrora famosa universidad, en una carta al "Heraldo de Madrid”, desautorizando la especie de que él también era partidario de la fundación "hispano-americana", ha puesto el dedo en la llaga, dándola, con su gran autoridad, un golpe terrible que habría sido de muerte si hubiese tenido aquella alguna vida. Expresa en esa carta el insigne filósofo y escritor, con ruda franqueza, lo que yo hube de callar al señor Rodríguez San Pedro y acompañantes, cohibido por elementales conveniencias, lo que no podría decir en público un estrangero en España sin grave riesgo personal y sin provocar formidables protestas. ${ }^{20}$

De Los gestos A LA ACCión

Con la misma rapidez con que saltó a las primeras páginas de los periódicos, el tema de la Universidad Hispanoamericana se desvaneció. Se ha llegado a sugerir que se trató de una broma de mal gusto a costa de la cual Cobos pudo pasarse unas vacaciones a cuerpo de rey en España. Hernández Díaz (405-06), uno de los pocos autores que ha escrito sobre el tema, no puede entender el porqué de este fracaso, aunque con acertada intuición se pregunta si la propuesta de las sociedades españolas en Argentina pudo ser acogida con recelo en otros sectores o en otras repúblicas. De hecho, no era la propuesta de las sociedades españolas sino de un sector de ellas, de ese sector de la élite intelectual de la colectividad afín a las ideas que en España defendía la Unión Iberoamericana. Frente a este sector, que Cobos representaba mejor que nadie, se alzaba otro que, percibiendo la opinión que en Argentina se tenía de España, reconocía la inviabilidad de las posturas que en España pretendían marcar el camino a los americanos. Se trataría, si acaso, de buscar juntos el camino, según el modelo que Unamuno y Grandmontagne, y Altamira y Atienza definían. La Unión perdió en esta campaña un prestigio que ya nunca volvería a recobrar. Prueba de ello es que los institucionistas no necesitaron ya volver a utilizar su cobertura para seguir empujando sus propuestas americanistas.

Los resultados de la acción de la Patriótica de Buenos Aires afectaron poco las estadísticas de comercio entre ambos países, pero sí fueron fecundos en el terreno de las

\footnotetext{
${ }^{20}$ Archivo de la Cancillería, caja 893, exp. 1. En el acuse de recibo, el ministro argentino de Relaciones Exteriores anota: "De acuerdo con las ideas expuestas por V. E., pienso a mi vez que esa idea no prosperará ni tendrá el éxito que persiguen los iniciadores por las razones que muy bien estudia y expone V.E.”
} 
relaciones intelectuales, siguiendo las pautas que Grandmontagne y Atienza habían sugerido a Unamuno y Altamira. Nuevos intereses acapararon pronto la atención de Unamuno alejándole de la militancia americanista. Grandmontagne, cita de los intelectuales argentinos que viajen por España a principios de siglo — Rojas (22-24) le dedicará el capítulo 2 de su Retablo español: "Un vigía amigo en la frontera vasca”- continuará en la brecha, pero será Altamira, de entre nuestros protagonistas, quien dé un nuevo impulso a este americanismo de acción con su triunfal viaje por América en 1909, organizado por la Universidad de Oviedo. De esta universidad, la iniciativa pasará, también en clave institucionista, a la Junta para Amplicación de Estudios, que comisionará el viaje de Posada en 1910. En Buenos Aires, ambos serán recibidos por Joaquín V. González, entonces presidente de la Universidad Nacional de La Plata que, gracias a su relación con Atienza, será quien transforme el hispanismo de gestos de los Oyuela, Sáenz Peña y Rubén Darío del 1898 en el hispanismo de acción de una década después. La colonia inmigrante española seguirá alentando estos contactos. Fallecido Atienza en 1906, la iniciativa dentro de la colonia corresponderá a quien, tras la marcha de Grandmontagne a España, fuera su mano derecha en la Patriótica: el también médico — este sí pincharía y cortaría mucho— Avelino Gutiérrez, catedrático de la Universidad de Buenos Aires.

Con la Patriótica en esos años bajo la presidencia de Ortiz y San Pelayo, Gutiérrez necesitó de un nuevo vehículo para hacer posible las ideas que había compartido con Atienza. Así nació la Institución Cultural Española, cuya función fue la de costear una cátedra en la Universidad de Buenos Aires en la cual impartirán sus cursos, nombrados por la Junta para Ampliación de Estudios, intelectuales de la talla de Menéndez Pidal, Ortega y Gasset, Rey Pastor y otros, cátedra que se le ofreció a Unamuno en 1916, pero que éste no quiso aceptar. Rubén Darío, por esas fechas, moría en su Nicaragua natal. Maeztu, otro intelectual que hemos visto cercano a Grandmontagne a principios de siglo, viajará en los veinte a Buenos Aires como embajador, y allí empezará a esbozar su concepto de hispanidad... pero eso es ya otra historia.

En todo caso, este americanismo de acción fomentado en España por la Universidad de Oviedo y la Junta, y este hispanismo de acción fomentado en Argentina por González y, luego, por la Universidad de Buenos Aires, no habría discurrido por los cauces por los que discurrió de no haberse entrecruzado en el Buenos Aires de 1898 las vidas de Darío y Grandmontagne en el remolino causado por la actuación de la Patriótica de los años heroicos de 1896-98 y de los años regeneracionistas de 1903-06.

Darío, Grandmontagne y la Patriótica aceleraron y dieron dirección a unos cambios que por lo demás no fueron sino manifestaciones puntuales de un fenómeno más amplio y de trascendencia continental. Este ascenso del hispanismo puede ligarse igualmente al surgimiento de un sentimiento antiyanki, presente ya en el '98 y que aflorará repetidamente en el siglo xx, al que, como analiza Charles Bergquist en un reciente estudio, Washington se verá obligado en numerosas ocasiones a responder. También, como señaló en su momento Carl Solberg, a la emergencia en la escena política del movimiento tradicionalista en países como la propia Argentina, de la que había quedado marginado tras la caída de Rojas, con la matización de que no es que a raíz del '98 el hispanófilo sector tradicionalista pase a un primer plano, sino que teniendo ahora los tradicionalistas un territorio común 
con un influyente sector de los liberales —el territorio del hispanismo— les va a ser más fácil ganar influencia en el futuro.

Los viajes de Darío y Grandmontagne a España — corresponsales de los periódicos más emblemáticos del subcontinante, La Nación el primero, La Prensa el otro- al enlazar las corrientes hispanistas de nuevo tipo que surgen tras el '98 con las corrientes americanistas vinculadas al regeneracionismo que aparecen poco después en la Península van a permitir que las élites intelectuales a ambos lados del Atlántico dialoguen, aportando así un elemento más a ese vuelco ideológico que se produce en Iberoamérica al comenzar el siglo xx.

\section{BiBLIOGRAFÍA}

Abellán, José Luis. Historia crítica del pensamiento español. Tomo 5/ii. Madrid: EspasaCalpe, 1989.

Allen, David. "Rubén Darío frente a la creciente influencia de los Estados Unidos". Revista Iberoamericana 64 (1967): 378-93.

Altamira, Rafael. “La universidad hispanoamericana”. España 75 (1905): 1-2. España en América. Valencia: F. Sempere, 1908.

Arrieta, Alberto. La literatura argentina y sus vínculos con España. Buenos Aires: Institución Cultural Argentina, 1948.

Atienza, Antonio. “La Universidad Hispanoamericana”. España 87 (1905): 3-4.

Balbuena Briones, Antonio. Literatura Hispanoamericana, 3 ed. Barcelona: Gustavo Gili, 1967.

Bergquist, Charles. Labor and the Course of American Democracy. Londres: Verso, 1996.

Calzada, Rafael. Cincuenta años en América. Notas autobiográficas, vol ii. Buenos Aires: Librería Jesús Menéndez, 1927.

Darío, Rubén. “El triunfo de Calibán”. El Tiempo (Buenos Aires, 20 de mayo de 1898). “El triunfo de Calibán”. Edición y notas de Carlos Jaúregui. Revista Iberoamericana 184-185 (1998): 451-55. Prosas profanas. Buenos Aires: La Vasconia, 1898.

Cantos de vida y esperanza: los cisnes y otros poemas. Barcelona: Atlante, s. f. España contemporánea. [1900]. Barcelona: Lumen, 1987.

Fernández, Rómulo. Historia del periodismo argentino. Buenos Aires: Perlado, 1943.

García, Ignacio. “... Y a sus plantas rendido un león: xenofobia antiespañola en Argentina”. Estudios Migratorios Latinoamericanos 39 (1998a): 195-222.

"Voluntarios españoles del Río de la Plata en la guerra de Cuba”. Cuadernos Hispanoamericanos 577/578 (1998b): 113-28.

Grandmontagne, Francisco. Teodoro Foronda. Evoluciones de la sociedad argentina. Buenos Aires: La Vasconia, 1896. La Maldonada. Costumbres criollas. Buenos Aires: La Imprenta Artística, 1898. "Por el Pilcomayo. Enrique de Ibarreta. Los tobas del Chaco argentino". La Ilustración Sudamericana, (1899): 29 y ss. 
Una gran potencia en esbozo. Buenos Aires: Institución Cultural Española, 1943.

Hernández Díaz, J. M. “La Universidad Hispano Americana. Un proyecto de principios del siglo xx”. Historia de las Relaciones Educativas entre España y América. M. C. Benso Calvo y otros. Sevilla: Universidad de Sevilla, 1988.

Herrera y Obes, Julio. “La cuestión palpitante”. El Tiempo (Buenos Aires, 21 de abril de 1898).

Jaúregui, Carlos. “Calibán, ícono del 98. A propósito de un artículo de Rubén Darío”. Revista Iberoamericana 184-185 (1998): 441-49.

Martínez Ruiz, Juan (Azorín). Obras completas vol 2. Madrid: Aguilar, 1947.

Oyuela, Calixto. “Oda a España”. El Tiempo de Buenos Aires, 3 de abril de 1898.

Pike, Frederick B. Hispanismo 1898-1936. Spanish Conservatives and Liberals and their Relations with Spanish America. South Bend (Indiana): University of Notre Dame Press, 1977.

Posada, Adolfo. “Cultura Hispanoamericana. Posición del problema de las relaciones científicas con América, desde España”. Boletín de la Institución Libre de Enseñanza, 2a época 14 (1992): 26 y ss.

Rama, C. M., Historia de las relaciones culturales entre España y América Latina. México: Fondo de Cultura Económica, 1982.

Rodó, José Enrique. “Rubén Darío. Su personalidad literaria”. La Ilustración Sudamericana (1898): 164-65.

Ariel. [1900]. Buenos Aires: Espasa Calpe, 1948.

Rojas, Ricardo. “Retablo español”. Obras completas, vol. 25. Buenos Aires: Losada, 1948.

Solberg, Charles. Immigration and Nationalism. Argentina and Chile, 1890-1914. Austin: University of Texas Press, 1970.

Tarnassi, José. "Per la Spagna. Cancione di guerra”. La Ilustración Sudamericana. Calixto Oyuela, trad. (1898): 186.

Tellechea Idígoras, J. Ignacio. El vasco Francisco Grandmontagne. San Sebastián: Sociedad Guipuzcoana de Ediciones y Publicaciones, 1990.

Unamuno, Miguel de. “Sobre la literatura hispanoamericana. A Rubén Darío”. La Nación (Buenos Aires, 19 de mayo de 1899).

“La Maldonada, costumbres criollas, por F. Grandmontagne”. La Época (Madrid, 10 de abril de 1899).

Varela, Luis V. “España y los Estados Unidos”. El Tiempo (Buenos Aires, 13 de abril de 1898). 